\title{
Laminar flame speed of different syngas compositions for varying thermodynamic conditions
}

\author{
R. Rabello de Castro ${ }^{1}$, P. Brequigny, J.P. Dufitumukiza, C. \\ Mounaïm-Rousselle \\ Université d'Orléans, INSA-CVL, PRISME, EA 4229, F45072 Orléans, France
}

\begin{abstract}
Syngas (for synthetic gas) is a well known gaseous biofuel, also known as producer gas or wood gas. It is composed mainly of $\mathrm{N}_{2}, \mathrm{CO}_{2}, \mathrm{CO}, \mathrm{H}_{2}$ and $\mathrm{CH}_{4}$, with varying shares depending on the gasification process and biomass source. When syngas is used in Internal Combustion engines for stationary electricity generation, the operation modes have to be adapted. The problem is that, for the moment, the combustion parameters of complex syngas compositions are not fully covered by the literature. In this study, the laminar flame speeds and Markstein lengths are measured for three syngas compositions. This compositions were chosen to represent typical production of three types of gasifiers (Updraft, Downdraft and Fluidized Bed). Measurements were made at varying initial temperatures ( 298 to $423 \mathrm{~K}$ ), pressures ( 1 to 5 bar) and equivalence ratios (0.6 to 1.4). The method used was the outwardly propagating spherical method. Higher $\mathrm{H}_{2}$ and $\mathrm{CO}$ contents on the Updraft and Downdraft compositions produced flame speeds two times higher than the Fluidbed composition. Results were compared to the data from the only two previous studies but no quantitative agreement was found. The results obtained from kinetic modeling with four kinetic mechanisms provide a global agreement specially those from the CRECK mechanism that only deviated from the experimental results by 5 to $10 \%$.
\end{abstract}

${ }^{1}$ Corresponding author: Ricardo Rabello de Castro E-mail Adress: ricardo.rabello@univ-orleans.fr

Preprint submitted to Fuel

May 26, 2021 
Keywords: Syngas, Laminar Flame Speed, Producer gas, wood gas.

\section{Introduction}

The global energy policy trend for the transition from fossil to renewable and carbon-neutral fuels is the main motivation for combustion research nowadays. The EU has established that by 2030 it would have reduced green house gases 5 emissions by $40 \%$ compared to the year 1990 [1]. One of the results of these emission goals is an increase in biofuel utilization on transportation and electricity generation, which has grown by over 50\% from 2008 to 2015 [2]. This growth trajectory is also visible in developing countries where fossil fuels are sometimes scarce and biofuel feedstock can be widely available [3]. In this context, the gasification process is one way to valorize biomass as low carbon fuel. Indeed, from this process, a gas, usually called syngas for synthetic gas, is obtained

Syngas utilization on Internal Combustion (IC) engines dates back to the second World War, when gasoline shortages stimulated the conversion of vehicles to fuel derived from wood gasification [4. But the use of syngas in IC engines nowadays has to be optimized, considering both efficiency (to limit the carbon footprint) and the exhaust emissions. Nonetheless, research on the characteristics of syngas fueled IC engines is limited [5, 6, 7, 8, 9, 10, 11, 12,

Syngas composition varies significantly with the biomass source and the gasification process used [13,18], but its main components are $\mathrm{CO}, \mathrm{H}_{2}, \mathrm{~N}_{2}$, $\mathrm{CO}_{2}$ and $\mathrm{CH}_{4}$. The composition will affect the combustion process itself and the pollutant species produced. In order to predict and improve the performance of an engine, key parameters of the combustion process must be determined beforehand. One important parameter is the laminar flame speed, $\mathrm{S}_{u}^{0}$, of the air-fuel mixture, which determines its usability under certain engine operating conditions. In the literature $S_{u}^{0}$ is defined as the speed at which a planar, adiabatic, unstretched, premixed flame propagates relative to the unburned gas mixture [13]. One method for measuring $S_{u}^{0}$ is the spherically propagating flame $[14,13,15]$ where the flame front history is recorded with high-speed Schlieren or 
shadowgraphy. The spherical flame method allows for measurements at varying initial pressures and temperatures, but within a limited range [14, 16, 17, 18]. This curbs the ability to predict $\mathrm{S}_{u}^{0}$ in engine-like conditions.

The majority of the work on syngas $\mathrm{S}_{u}^{0}$ focused on $\mathrm{H}_{2} / \mathrm{CO}$ mixtures with diluents [19, 16, 20, 17, 18]. The ratio between $\mathrm{H}_{2}$ and $\mathrm{CO}$ mole fractions is one of the major parameters for determining the overall quality of the fuel.

35 Bouvet et al. 18 measured, by shadowgraphy of spherically propagating flames, laminar flame speeds of mixtures with $\mathrm{H}_{2} / \mathrm{CO}$ ratios ranging from 0.052 to 1. Their results showed that, by increasing hydrogen content from 0.052 to 1 the mixture's maximum flame speed $\left(S_{u_{\max }}^{0}\right)$ increases from around 60 to 180 $\mathrm{cm} / \mathrm{s}$. Other research included $\mathrm{CH}_{4}$ and $\mathrm{CO}_{2}$ addition [21, 22, 23, which also 40 influences $\mathrm{S}_{u}^{0}$. Lapalme et al. 21] tested the effect of $\mathrm{CH}_{4}, \mathrm{CO}$ and $\mathrm{CO}_{2}$ addition in spherically propagating flame stability, with $\mathrm{H}_{2} / \mathrm{CO}$ ratios ranging from 0.33 and 7.5. Zhou et al. 23] studied the effect of the dilution of a $\mathrm{H}_{2} / \mathrm{CO} / \mathrm{CH}_{4}$ fuel mixture with $\mathrm{CO}_{2}$ and $\mathrm{N}_{2}$ separately for varying pressures. Zhou concluded that both elevated pressures induced an early onset of flame instabilities (wrinkles) and that flame stretch sensitivity increased with $\mathrm{N}_{2}$ and $\mathrm{CO}_{2}$ dilution.

Different from the work mentioned above, the work by Monteiro et al. 24, 25] investigated three compositions representing the typical production of the following types of gasifiers:

- Downdraft: fixed-bed gasifier where the product flow is recovered on the bottom of the reactor, following the same direction as the downwardmoving biomass introduction;

- Updraft: fixed-bed gasifier where the product is recovered on the top of the reactor, flowing in the opposite direction to the downward-moving biomass;

- Fluidbed: where biomass is mixed in a inert solid (sand for example).

Monteiro et al. 24] used the spherically propagating flame technique to measure laminar flame speeds for the three compositions detailed in Table 1 at normal 
Table 1: Typical syngas properties of syngas compositions from

\begin{tabular}{|c|c|c|c|c|c|c|c|c|c|c|c|}
\hline & $\mathrm{H}_{2}$ & $\mathrm{CO}$ & $\mathrm{CO}_{2}$ & $\mathrm{CH}_{4}$ & $\mathrm{~N}_{2}$ & LHV & $\begin{array}{l}\text { Air fuel ratio } \\
\left(A F R_{s t}\right)\end{array}$ & $\frac{\rho_{u}}{\rho_{b}}$ & $\begin{array}{c}\text { Flame } \\
\text { Thickness }\end{array}$ & $\begin{array}{c}\text { Maximum Flame } \\
\text { Speed }\left(S_{u}^{0}\right)\end{array}$ & $\begin{array}{c}\text { Maximum } \\
\mathrm{T}_{a} d\end{array}$ \\
\hline & $\% \mathrm{Vol}$ & $\% \mathrm{Vol}$ & $\% \mathrm{Vol}$ & $\% \mathrm{Vol}$ & $\% \mathrm{Vol}$ & $\mathrm{MJ} / \mathrm{m}^{3}$ & - & - & $\mathrm{mm}$ & $\mathrm{cm} / \mathrm{s}$ & $\mathrm{K}$ \\
\hline Fluidized Bed (Fluidbed) & 9 & 14 & 20 & 7 & 50 & 4.2 & 1.21 & 0.18 & 0.651 & 15.4 & 1780 \\
\hline UpDraft & 11 & 24 & 9 & 3 & 53 & 4.4 & 1.12 & 0.18 & 0.375 & 30.7 & 1900 \\
\hline DownDraft & 17 & 21 & 13 & 1 & 48 & 4.8 & 1.00 & 0.18 & 0.364 & 36.7 & 1870 \\
\hline
\end{tabular}

temperature and pressure conditions and equivalence ratios ranging from 0.6 to 1.2. Monteiro found that, on average, $\mathrm{S}_{u}^{0}$ values for downdraft and updraft mixtures are, respectively, 14 and $8 \mathrm{~cm} / \mathrm{s}$ higher than those of fluidbed mixtures. Monteiro and Rouboa [25] expanded on their previous work by including initial pressure variation from 1 to 20 bar but with limited variation on the equivalence ratio $(0.8,1.0$ and 1.2$)$.

Laminar flame speeds can be measured but can also be obtained through simulation. The majority of kinetic mechanisms available for syngas are validated for the main components of syngas but individually and not mixed together. This is the case for the NUI Galway [26] mechanism that, despite being thoroughly validated with measured flame speeds of $\mathrm{H}_{2}$ and $\mathrm{CO}$ mixtures, did not perform well when predicting $S_{u}^{0}$ for the compositions tested here. Another common limitation of the mechanisms is that usually only validated with laminar flame speeds for a narrow temperature and pressure range. The availability of $\mathrm{S}_{u}^{0}$ data for real-world syngas compositions, at a wide range of thermodynamic conditions, is necessary to confirm that a mechanism can be used for CFD simulation.

Despite the fact that steam and oxygen-fed gasifiers produce syngas mixtures with higher heating values, air-fed gasifiers are the most common and, therefore, are the ones considered in this study. Because of the high concentration of inert gases (over 50\%), lower heating values (LHV) are relatively low, ranging from 4 to $7 \mathrm{MJ} / \mathrm{Nm}^{3}$ for air-fed gasification [27].

so This work aims to create a database of laminar speeds for a wide range of temperatures, pressures and equivalence ratios and for each composition of syngas. This database will assist in the validation of reaction mechanisms for 
syngas combustion. From this database, a correlation between these parameters and the laminar flame speed, similar to the one proposed by [28], will be discussed.

The paper begins with the description of the physical experimental setup followed by a discussion on the post-processing strategy and uncertainty analysis. In the Results and Discussion section the kinetic mechanisms are presented and laminar flame speeds are compared to both literature and simulation data. The correlation for each composition is presented and the accuracy of the correlation results is compared to the ones of the kinetic mechanisms and to a correlation proposed by Monteiro and Rouboa [25]. The Markstein length results are discussed and compared to results from Monteiro et al. 24]. In the final section the main conclusions are drawn and future perspectives discussed.

\section{Experimental Setup}

The setup used in the determination of laminar flame speed consists of a optically-accessible spherical vessel, a laboratory system to simulate syngas using flowmeters and a Schlieren optical setup coupled with a high-speed camera. The setup main characteristics are presented here, and more fully described in previous works [29, 15, 30, 31, 32.

The spherical vessel is a $4.2 \mathrm{~L}$, stainless steel sphere with a $200 \mathrm{~mm}$ inner diameter and optical access is granted by four quartz windows of $70 \mathrm{~mm}$ in diameter. A vacuum pump depletes the sphere of gases dropping the pressure to below 10 mbar. Six gaseous flowmeters are connected to the intake of the sphere and insure that, by the end of the filling process, the specified mixture composition and initial pressure are obtained. During this filling process a fan spins, guaranteeing homogeneity, and it is stopped 20 seconds before the ignition. For initial temperature control, heating elements are placed around the combustion chamber and in the intake tube allowing for temperatures up to $473 \mathrm{~K}$ at the beginning of the test. The ignition system is composed of a automotive coil-on-plug connected to two $0.5 \mathrm{~mm}$ thick electrodes with a 1.5 
$\mathrm{mm}$ gap between them. Ignition charge time is set at $3 \mathrm{~ms}$ resulting in $100 \mathrm{~mJ}$ of discharge energy. The test conditions are detailed in Table 2 , based on the three types of syngas composition and thermodynamic conditions as close as possible to those at the time of ignition in a Spark-Ignition engine. Three repetitions are made for each condition with the exception of the updraft composition at equivalence ratios 1.0 and 1.4 at $298 \mathrm{~K} 1$ bar where one of the shots deviated significantly from the other two so they were removed.

\subsection{Optical setup and post-processing method}

The high-speed Schlieren setup used on this work is presented on figure 1. The light from the LED (CBT120) passes through a parabolic mirror that produces a parallel beam. The second parabolic mirror focuses on the cutoff point placed between lenses 1 and 2, which focuses the beam on the camera sensor. The camera used on the experiments is a High Speed Phantom V1610, set to record at 7000 frames-per-second with a resolution of $640 \times 800$ pixels $^{2}$ and a spatial resolution of $0.11 \mathrm{~mm} /$ pixel.

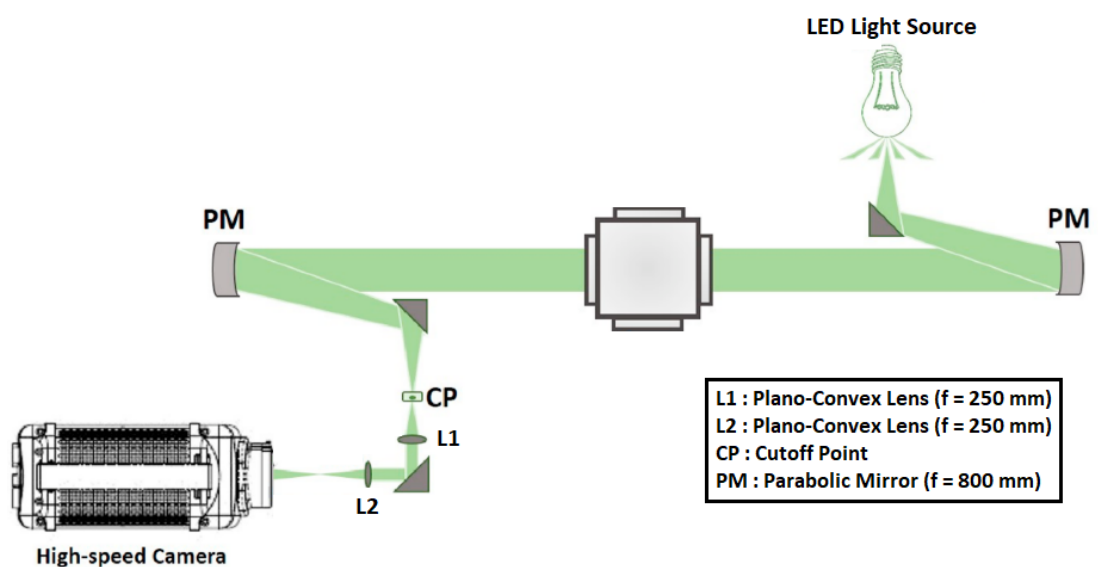

Figure 1: Schlieren Optical Setup.

Post-processing, performed in the Matlab environment, is described in the work by Di Lorenzo et al. 29. First, the images are subtracted by the back- 
ground, binarized by a specific chosen threshold, and filtered by a low-pass filter to reduce noise on the contour of the flame front. For each frame, a contour is defined by "filling" the empty areas with the dilation/erosion technique. The corresponding radius is given by Equation 1. Figure 2 is an example of the results of the contour detection routine.

$$
R_{f}=\sqrt{\frac{A}{\pi}}
$$

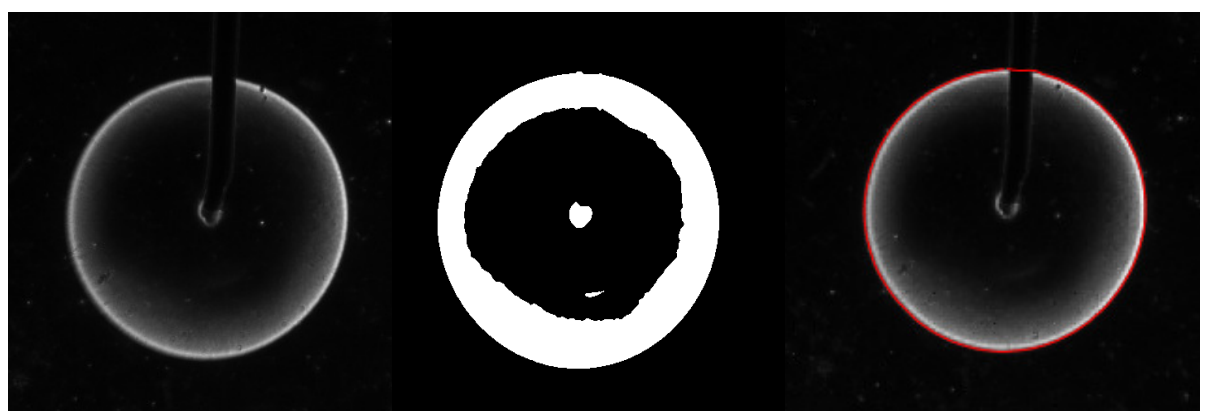

Figure 2: Post-processing steps illustrated by the unprocessed image (left), the binarized image (center) and the resulting flame contour traced over the unprocessed image (right).

Table 2: Experimental test conditions

\begin{tabular}{|c|c|c|c|c|c|c|c|c|}
\hline Syngas Composition & \multicolumn{3}{|c|}{ Downdraft, Updraft } & \multicolumn{3}{c|}{ Fluidized Bed } \\
\hline Equivalence Ratio & \multicolumn{3}{|c|}{$0.6-1.4$} & \multicolumn{3}{c|}{$0.6-1.2$} \\
\hline Pressure (bar) & 1,3 and 5 & \multicolumn{2}{|c|}{1} & 1,3 and 5 & \multicolumn{3}{c|}{1} \\
\hline Temperature (K) & 323 & 298 & 373 & 423 & 323 & 298 & 373 & 423 \\
\hline
\end{tabular}

Once the flame radius over time profile is obtained, the speed and stretch profiles can be calculated as follows [15]:

$$
S_{b}=\frac{d R_{f}}{d t} \quad K=\frac{2}{R_{f}} \frac{d R_{f}}{d t}
$$

Using the stretch and speed profiles, the stretched flame speed $\left(S_{b}\right)$ can be extrapolated to unstretched laminar flame speed $\left(S_{b}^{0}\right)$, using a non-linear quasisteady extrapolation (Eq 3) proposed by Kelley and Law 33] and validated 
by Halter et al. 34] for methane/air and isooctane/air flames. $L_{b}$ being the Markstein length.

$$
\left(\frac{S_{b}}{S_{b}^{0}}\right)^{2} \ln \left(\frac{S_{b}}{S_{b}^{0}}\right)^{2}=-\frac{2 L_{b} K}{S_{b}^{0}}
$$

Gong et al. 35. has evaluated the accuracy of four extrapolation methods for $\mathrm{H}_{2} / \mathrm{CO}$ mixtures by comparing extrapolation results to DNS-mapping. The non-linear quasi-steady extrapolation used here was more accurate than the linear extrapolations based on stretch and curvature. The non-linear extrapolations with and without flame thickness consideration resulted on very similar laminar flame speed values. The radius limits for the extrapolation were chosen in a shot-by-shot basis following the guidelines proposed by Han et al. [36]. Finally, the unburned laminar flame speed is given by $S_{u}^{0}=\frac{\rho_{b}}{\rho_{u}} S_{b}^{0}$, where $\rho_{b}$ and $\rho_{u}$ are the burned and unburned gas densities, respectively calculated by the equilibrium model in Ansys Chemkin-Pro. 


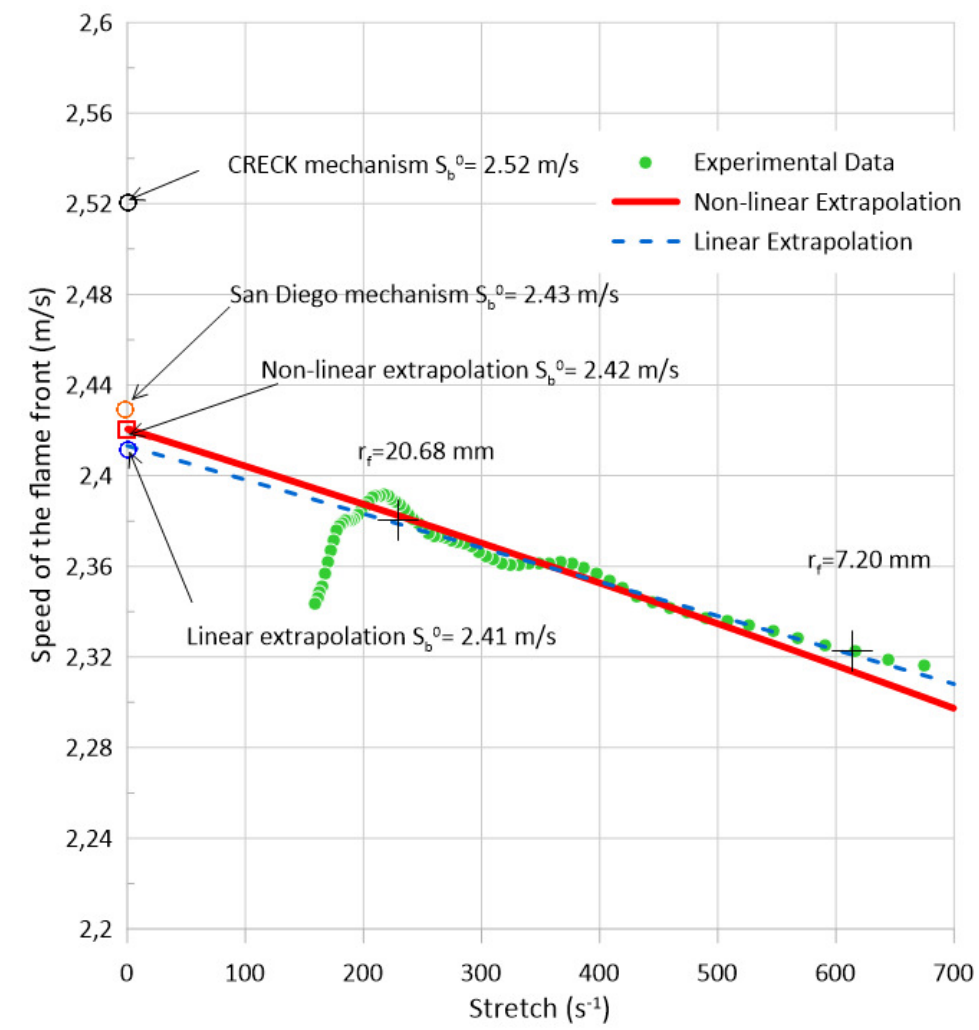

Figure 3: Flame speed plotted over stretch for the downdraft composition at 1 bar $373 \mathrm{~K}$ and $\phi=1.2$.

Figure 3 compares the results of the non-linear (used in this work) and linear extrapolations to the simulation results from two mechanisms. It can observed that both extrapolation methods give satisfactory results in this case with extrapolation results deviating less then $10 \%$ from the simulation results. It is also clear the importance of the choice of extrapolation limits: for faster flames like this one speed of the flame front decreases sharply at around $K=200 s^{-1}$ due to pressure effects. 


\subsection{Uncertainty Analysis}

Based on the work of Brequigny et al. [37, the overall uncertainty $B_{S_{u}^{0}}$, can be estimated as:

$$
B_{S_{u}^{0}}=\sqrt{\left(\frac{\Delta S_{u}^{0}}{S_{u}^{0}}\right)_{P, T, \phi}^{2}+\left(\frac{\Delta S_{u}^{0}}{S_{u}^{0}}\right)_{\text {imaging }}^{2}+\left(\frac{\Delta S_{u}^{0}}{S_{u}^{0}}\right)_{\text {statistical }}^{2}}
$$

The three components on Equation 4 represent, from left to right, experimental hardware errors, imaging errors and statistical errors.

Given the fact that in this experiment there are six mass flowmeters (BROOKS $5850 \mathrm{~S} 2 \mathrm{NL} / \mathrm{min}$ for air and $\mathrm{N}_{2}, 1.2 \mathrm{NL} / \mathrm{min}$ for $\mathrm{CO}$ and $0.5 \mathrm{NL} / \mathrm{min}$ for the other gases), with an error of $\pm 1 \%$ of full scale, the uncertainty for the equivalence ratio is estimated to be around \pm 0.02 . The temperature of the gases in the vessel is measured by a K-type thermocouple and the deviation from the set temperature can be up to $1 \%$ for the $298 \mathrm{~K}$ case, where the effect of hot burnt gases heating the vessel is more pronounced. Pressure before ignition is measured by a piezoelectric pressure transducer with an associated uncertainty of $\pm 2 \%$. Overall hardware related uncertainty can be calculated by Equation 5

$$
\left(\frac{\Delta S_{u}^{0}}{S_{u}^{0}}\right)=\sqrt{\left(|\alpha| \frac{\Delta T}{T}\right)^{2}+\left(|\beta| \frac{\Delta P}{P}\right)^{2}}
$$

Considering that the worst case scenario for the coefficients $\alpha$ and $\beta$ are 3.33 and -0.6 the hardware related uncertainty is $3.50 \%$.

The global imaging error was previously determined by Bréquigny et al. [37. and Lhuillier et al. [15] to be $2.5 \%$ for the same experimental setup.

Statistical error varies from below $1 \%$ to above $10 \%$ when conditions are not ideal (slow flame and low equivalence ratios).

Regarding the uncertainty related to radiation losses it can be concluded, based on Chen's [38] work and the concentration of $\mathrm{CO}_{2}$ on the tested syngas compositions, that the effects of radiation can be neglected.

\subsection{Laminar flame speed simulation}

The Ansys Chemkin-Pro PREMIX code is used to obtain unstretched laminar flame speeds at the different test conditions, in order to access the validity 
of chemical kinetic mechanisms. The model consists of a freely-propagating premixed laminar flame with adaptive grid and mixture-average transport properties. The Soret effect (thermal diffusion) was considered due to the presence of $\mathrm{H}_{2}$ in the compositions. Final GRAD and CURV parameters were set to 0.1 . Several kinetic mechanisms were tested and the ones that showed the more promising results were San Diego's [39], CRECK [40, Madison [41] and AramcoMech 3.0 [42] In Table 3 a description of the selected mechanisms is presented.

Table 3: Mechanisms description.

\begin{tabular}{|c|c|c|c|c|}
\hline Mechanism & Type & Fuel & Number of Species-Reactions & Validation by \\
\hline CRECK & Detailed & Syngas $\mathrm{C}_{0}-\mathrm{C}_{3}$ & $114-1999$ & Ignition delay, $\mathrm{S}_{u}^{0}$ \\
\hline San Diego & Short & $\mathrm{C}_{1}-\mathrm{C}_{4}$ & $47-257$ & Ignition delay, $\mathrm{S}_{u}^{0}$ \\
\hline Madison & Reduced & $\mathrm{C}_{10}-\mathrm{C}_{16}$ & $178-758$ & Ignition delay, $\mathrm{S}_{u}^{0}$ \\
\hline AramcoMech 3.0 & Detailed & $\mathrm{C}_{0}-\mathrm{C}_{10}$ & $581-3037$ & Ignition delay, $\mathrm{S}_{u}^{0}$ \\
\hline
\end{tabular}

\section{Results and Discussion}

In this section present work results will be compared to the results found in the literature and to results obtained from simulation.

\subsection{Laminar Flame Speed}

Laminar flame speed results show that the Updraft and Downdraft compositions produce flames that are around two times faster than those of the fluidbed compositions for the same conditions. This is consistent with the higher $\mathrm{H}_{2}$ and $\mathrm{CO}$ contents in those two compositions. The flame speed of the Downdraft composition is slightly higher than the Updraft and, at least at $298 \mathrm{~K} 1$ bar, is very similar to the flame speed of methane/air mixtures.

Only two studies focused on the determination of laminar flame velocity for the exact typical Syngas compositions, as defined by Bridgwater [27. Monteiro et al. 24 measured $S_{u}^{0}$ of three main Syngas compositions using schlieren imaging of a flame, expanding in a rectangular constant volume chamber. Oliveira et 
al. tested the downdraft composition on a Bunsen burner setup coupled with OH PLIF imaging. Only Oliveira et al. included simulation results to compare with their experimental data. In figure 4 unstretched is plotted over the global equivalence ratio calculated following equation 6 .

$$
\phi=\frac{A F R_{s t}}{\frac{\text { Air }_{\% \text { vol }}}{\text { Syngas\%vol }}}
$$

Figure 4 shows that the results of Monteiro et al. are in good agreement for downdraft and updraft lean mixtures. Results from Oliveira et al. 43] apparently 185 do not correspond to this work or to Monteiro's. It should be pointed out that results from the Bunsen burner technique, used by Oliveira et al [43], are strongly influenced by the inlet stream velocity and, even when well calibrated, are only accurate to around $6 \%$ 44. 


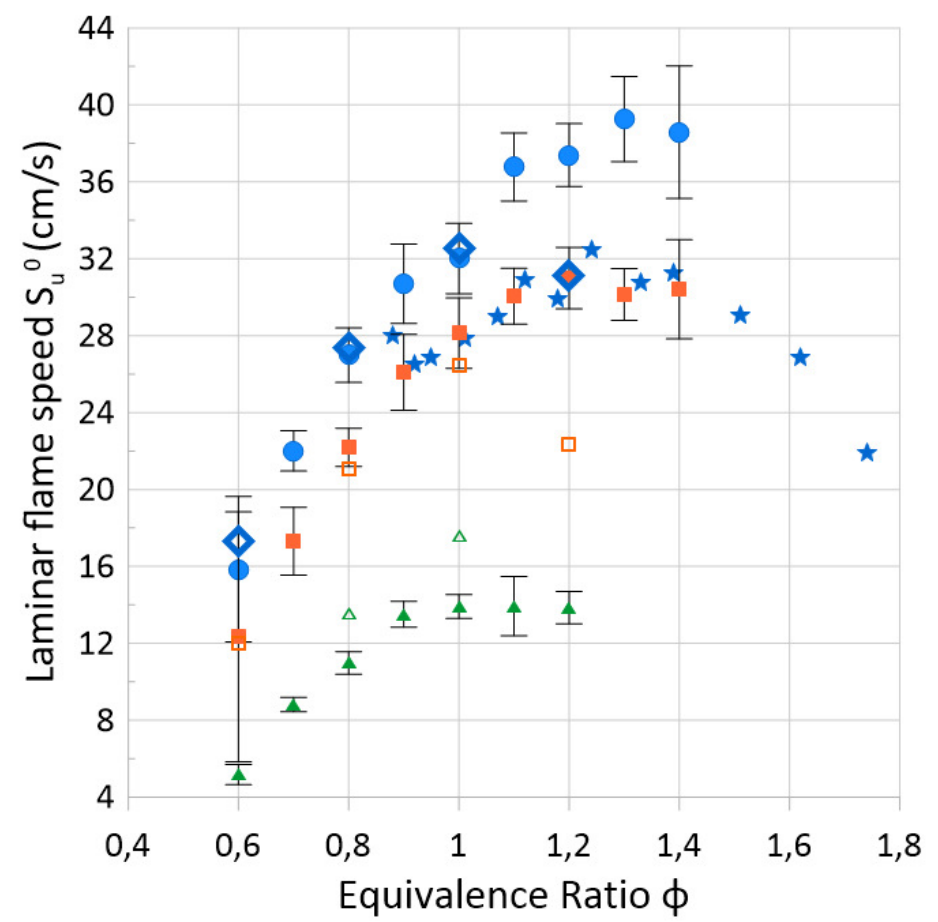

- Present Work - Downdraft $\square$ Monteiro et al. - Updraft

$\star$ Oliveira et al. - Downdraft $\Delta$ Present Work - Fluidbed

$\diamond$ Monteiro et al. - Downdraft $\Delta$ Monteiro et al.- Fluidbed

- Present Work - Updraft

Figure 4: Comparison of present work $\mathrm{S}_{u}^{0}$ results at 1 bar $298 \mathrm{~K}$ with results from Monteiro et al. 24] (1 bar $293 \mathrm{~K})$ and Oliveira et al. (0.954 bar $298 \mathrm{~K})$. 

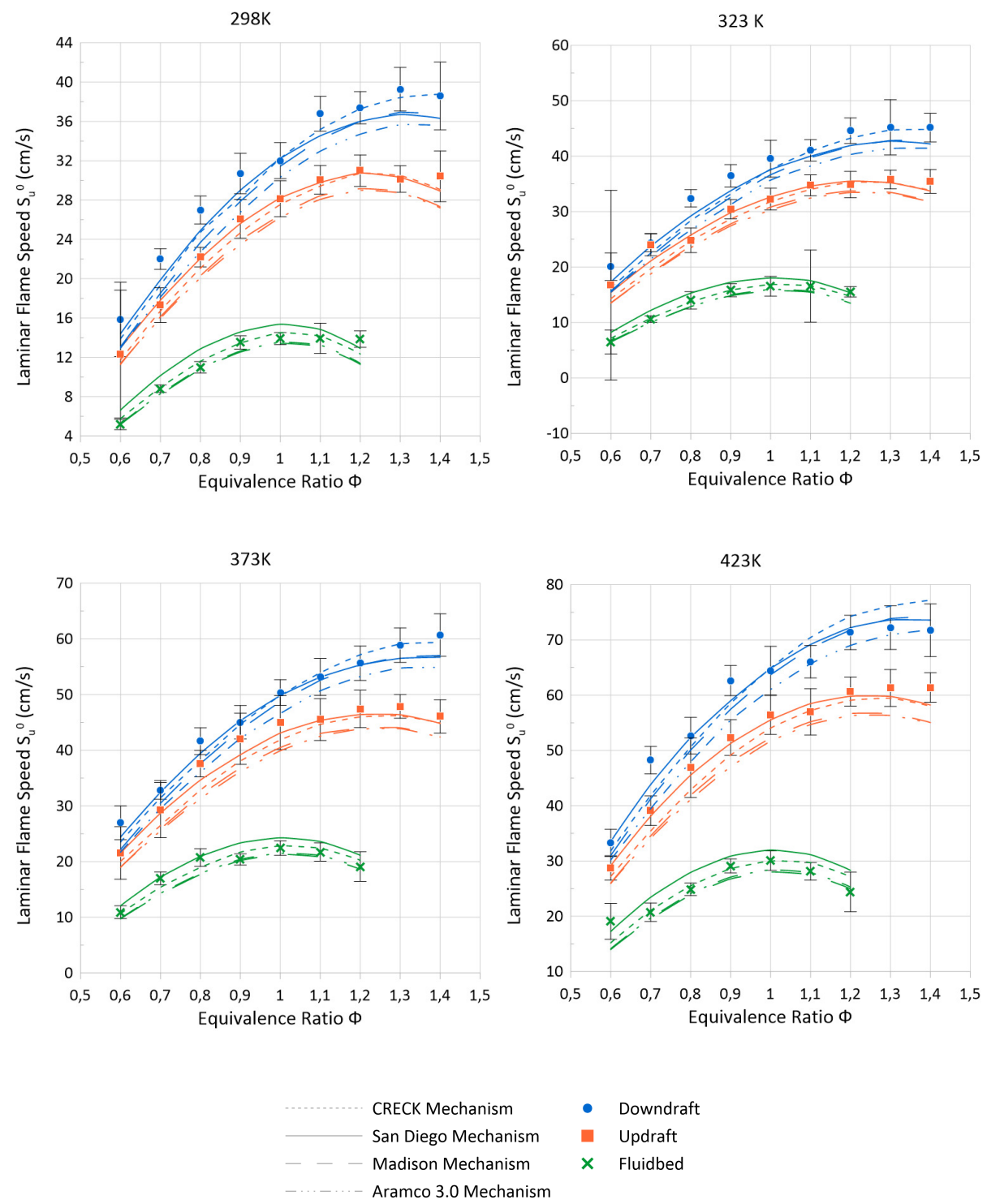

Figure 5: Experimental and simulated $\mathrm{S}_{u}^{0}$ results at 1 bar for four initial temperatures (298, $323,373$ and $423 \mathrm{~K})$.

Figure 5 shows a reasonable fit between the experimental results and the mechanisms, for all types of syngas, without significant change with temperature. These results indicate that the mechanisms are well optimized for the 
tested temperature range. The equivalence ratio corresponding to the maximum $S_{u}^{0}$ value and the $S_{u}^{0}$ values themselves are also well predicted within the uncertainty intervals. The $S_{u}^{0}$ values for the downdraft and fluidbed compositions are well predicted by the CRECK mechanism, whereas the updraft results seem to be closer to the San Diego's predictions.
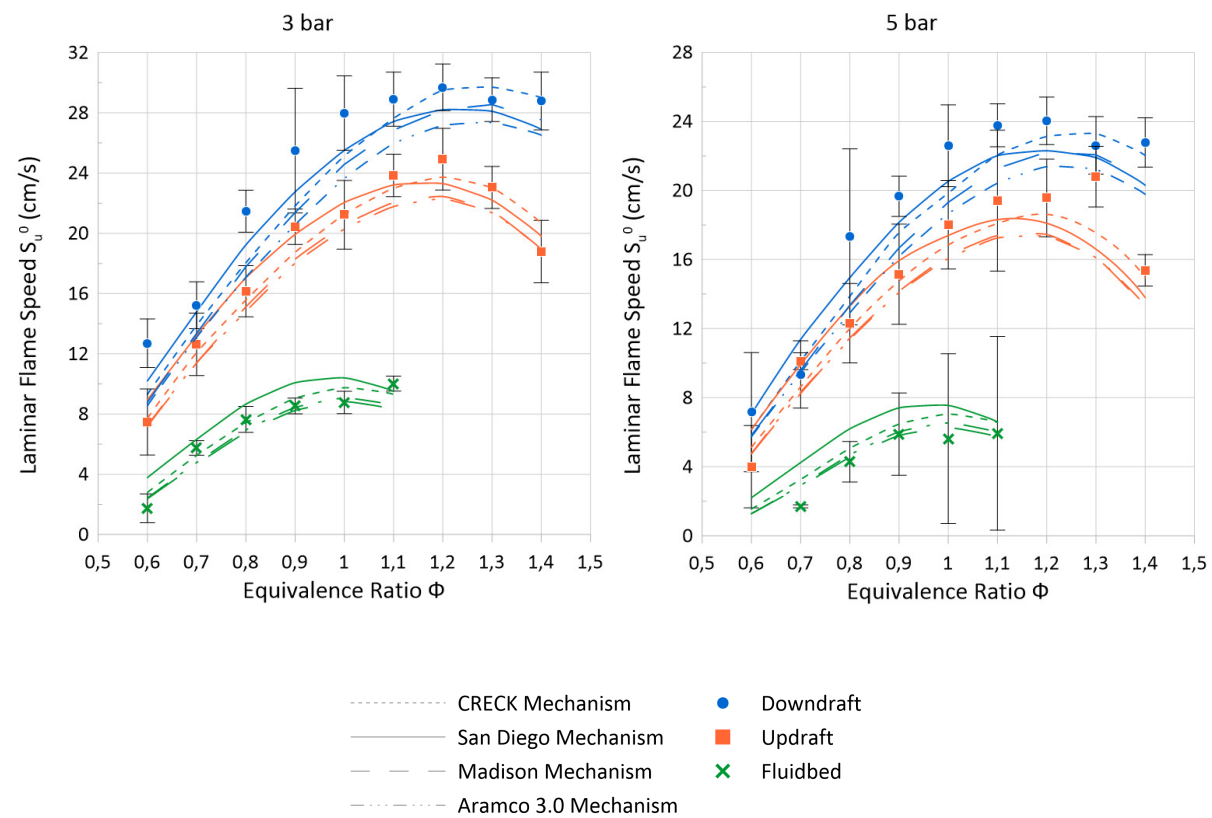

Figure 6: Experimental and simulated $\mathrm{S}_{u}^{0}$ results at $323 \mathrm{~K}$ initial temperature for 3 and 5 bar.

Over-ambient pressure results shown in Figure 6, reveal that all mechanisms can still predict, mostly within the experimental uncertainty intervals. These results are maintained even at those higher pressures, where buoyancy (slow flames of fluidbed mixtures) and thermal diffusive instabilities (high hydrogen content in downdraft composition) are more pronounced increasing shot-to-shot variability and, as a consequence, the statistical uncertainty. Those effects are minimized in the post-processing phase by reducing the treatment window and, therefore, avoiding the greater radiuses where cellularities and flame deformations tend to appear. This window reduction is limited by the minimum flame radius which is dictated by the end of the ignition effect on the flame and the un- 
certainty in the extrapolation which increases with less data points and smaller flame radii [45, 44]. The San Diego mechanism diverges from the experimental data when the initial pressure is increased for all syngas compositions but this is not the case for the other mechanisms. In fact, the average deviation from the experimental values for the CRECK mechanism even decreases from 9 to 3 $\%$ going from 3 to 5 bar for fluidbed. The difference in performance between the two mechanisms might be due the fact that, contrary to the CRECK mechanism, the San Diego mechanism has not been validated on flame speed for over-ambient pressures 39].

Table 4: Error between mechanism predictions and experimental results for downdraft.

\begin{tabular}{|c|c|c|c|}
\hline Mechanism & Average Error (\%) & Median Error (\%) & Maximum Error (\%) \\
\cline { 1 - 2 } CRECK & 7.82 & 6.08 & 30.26 \\
\cline { 1 - 1 } San Diego & 7.46 & 7.10 & 23.61 \\
\cline { 1 - 1 } AramcoMech & 13.15 & 11.41 & 35.98 \\
\cline { 1 - 2 } Madison & 10.31 & 8.69 & 34.20 \\
\hline
\end{tabular}

Table 4 confirms that the San Diego and CRECK mechanisms are in agreement with the experimental data. The comparatively high maximum error (24 to $36 \%$ ) is associated with the $\phi=0.6$ at 3 bar case where all mechanisms under-predict $S_{u}^{0}$.

Table 5: Error between mechanism predictions and experimental results for updraft.

\begin{tabular}{|c|ccc|}
\hline Mechanism & Average Error (\%) & Median Error (\%) & Maximum Error (\%) \\
\cline { 1 - 2 } CRECK & 5.62 & 4.49 & 28.14 \\
\cline { 1 - 1 } San Diego & 5.11 & 3.01 & 53.64 \\
\cline { 1 - 1 } AramcoMech & 9.7 & 9.08 & 22.55 \\
\cline { 1 - 3 } Madison & 9.02 & 8.49 & 22.58 \\
\hline
\end{tabular}

In Table 5 average and median errors for updraft mixtures are smaller than those obtained for downdraft mixtures. It is important to note that the average 
errors for all mechanisms are below $10 \%$.

Table 6: Error between mechanism predictions and experimental results for fluidbed.

\begin{tabular}{|c|c|c|c|}
\hline Mechanism & Average Error (\%) & Median Error (\%) & Maximum Error (\%) \\
\cline { 1 - 2 } CRECK & 9.66 & 5.62 & 91.8 \\
\cline { 1 - 1 } San Diego & 19.07 & 10.57 & 149.35 \\
\cline { 1 - 1 } AramcoMech & 9.38 & 5.51 & 71.78 \\
\cline { 1 - 2 } Madison & 9.69 & 6.33 & 67.85 \\
\hline
\end{tabular}

Table 6 shows that the CRECK mechanism accurately predicts the burning velocity for fluidbed mixtures. The San Diego mechanism, which predicts well

${ }_{225} \mathrm{~S}_{u}^{0}$ for updraft and downdraft, cannot provide accurate values in the case of fluidbed mixtures.

It can be concluded, for the three syngas compositions, that the CRECK and AramcoMech mechanisms are the most accurate of the mechanisms tested here.

The Madison mechanism also provides acceptable predictions of flame speed of the three syngas compositions, despite being developed for heavier fuels.

\subsection{Laminar Flame Speed Dependance On Inital Pressure and Temperature}

Based on the experimental results we have fitted a correlation adapted from Metghalchi and Keck 28, given by:

$$
S_{u}^{0}=S_{u_{r e f}}^{0}\left(\frac{T}{T_{0}}\right)^{\alpha}\left(\frac{P}{P_{0}}\right)^{\beta} .
$$

The following equations define the optimal coefficients for each of the three syngas compositions as a function of equivalence ratio. Equations 8,9 and 10 refer, respectively, to the downdraft, updraft and fluidbed compositions.

$$
\begin{array}{r}
S_{u_{r e f}}^{0}=-39.3811 \phi^{2}+107.0644 \phi-34.0178 \\
\alpha=1.338 \phi^{2}-3.249 \phi+3.759 \\
\beta=-1.124 \phi^{2}+2.444 \phi-1.662
\end{array}
$$




$$
\begin{array}{r}
S_{u_{r e f}}^{0}=-50.091 \phi^{2}+121.876 \phi-42.518 \\
\alpha=3.280 \phi^{2}-7.249 \phi+5.869 \\
\beta=-1.608 \phi^{2}+3.509 \phi-2.258 \\
S_{u_{r e f}}^{0}=-40.604 \phi^{2}+87.144 \phi-32.47 \\
\alpha=3.873 \phi^{2}-9.621 \phi+7.712 \\
\beta=-4.644 \phi^{2}+9.309 \phi-5.241
\end{array}
$$

235 Given the coefficients obtained from the equations above, $\mathrm{S}_{u}^{0}$ was calculated for each experimental data point. Figure 7 shows a comparison of the correlation presented above and the one proposed by Monteiro and Rouboa [25, for the same syngas compositions.
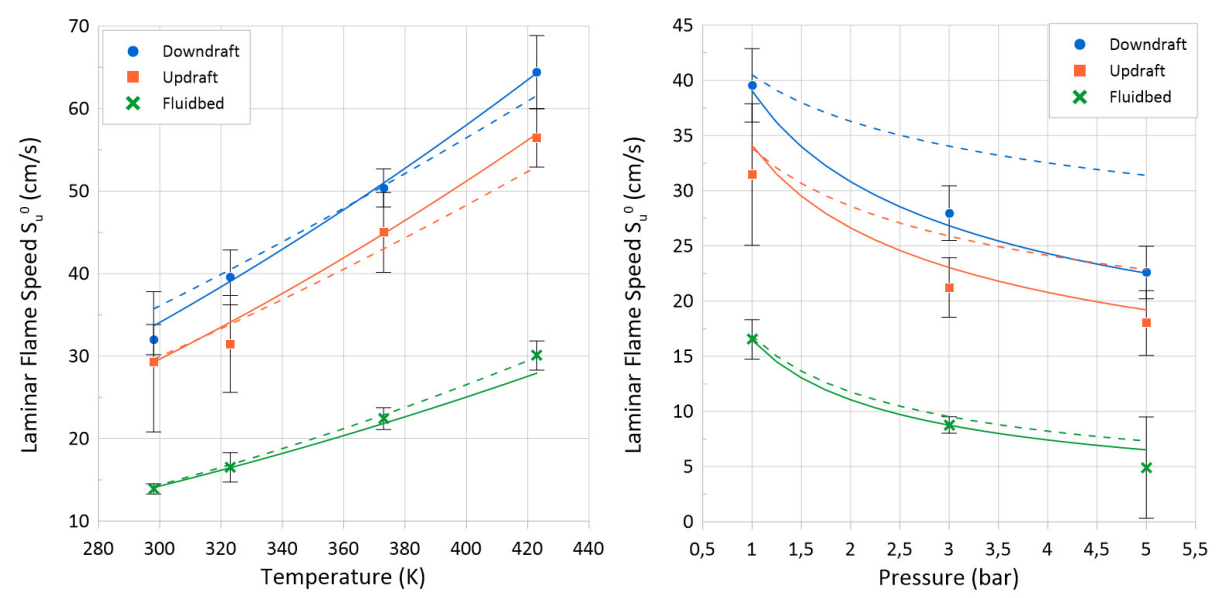

Figure 7: Comparison of current work correlation (solid line) and Monteiro and Rouboa 25] (dashed line) agreements with experimental data.

Table 7: Errors for correlation predictions and experimental measurement.

\begin{tabular}{|c|c|c|c|}
\hline Syngas Composition & Average Error (\%) & Median Error (\%) & Maximum Error (\%) \\
\cline { 1 - 4 } Downdraft & 3.64 & 2.16 & 22.42 \\
\cline { 1 - 2 } Updraft & 4.07 & 2.57 & 23.75 \\
\cline { 1 - 3 } Fluidbed & 6.42 & 3.06 & 36.8 \\
\hline
\end{tabular}


Table 7 presents the error of the correlation predictions for all data points. The correlation works best for downdraft mixtures. The maximum errors seem to concentrate on lean mixtures at higher pressures.

Table 8: Temperature and pressure dependence coefficients for different equivalence ratios fitted on experimental and mechanism data.

\begin{tabular}{|c|c|c|c|c|c|c|c|}
\hline & & \multicolumn{3}{|c|}{$\alpha$} & \multicolumn{3}{c|}{$\beta$} \\
\hline \multirow{5}{*}{ Downdraft } & $\phi=0.8$ & $\phi=1.0$ & $\phi=1.2$ & $\phi=0.8$ & $\phi=1.0$ & $\phi=1.2$ \\
\cline { 2 - 8 } & Experimental & 2.02 & 1.85 & 1.79 & -0.43 & -0.34 & -0.35 \\
\cline { 2 - 8 } & Creck Mechanism & 2.13 & 1.98 & 1.92 & -0.45 & -0.38 & -0.38 \\
\cline { 2 - 8 } & UCSD Mechanism & 2.15 & 1.98 & 1.94 & -0.42 & -0.37 & -0.38 \\
\cline { 2 - 8 } & AramcoMech & 2.16 & 1.99 & 1.93 & -0.45 & -0.38 & -0.38 \\
\hline \multirow{5}{*}{ Updraft } & Madison & 2.18 & 2.00 & 1.94 & -0.46 & -0.39 & -0.38 \\
\cline { 2 - 8 } & Experimental & 2.17 & 1.90 & 1.89 & -0.48 & -0.36 & -0.36 \\
\cline { 2 - 8 } & Creck Mechanism & 2.10 & 1.87 & 1.84 & -0.45 & -0.38 & -0.39 \\
\cline { 2 - 8 } & UCSD Mechanism & 2.09 & 1.90 & 1.88 & -0.42 & -0.37 & -0.41 \\
\cline { 2 - 8 } & AramcoMech & 2.07 & 1.92 & 1.89 & -0.45 & -0.38 & -0.40 \\
\hline \multirow{5}{*}{ Fluidbed } & Madison & 2.09 & 1.92 & 1.88 & -0.46 & -0.38 & -0.41 \\
\cline { 2 - 8 } & Experimental & 2.49 & 1.96 & 1.74 & -0.77 & -0.58 & -0.76 \\
\cline { 2 - 8 } & Creck Mechanism & 2.25 & 2.09 & 2.22 & -0.62 & -0.53 & -0.60 \\
\cline { 2 - 8 } & UCSD Mechanism & 2.22 & 2.08 & 2.23 & -0.56 & -0.53 & -0.66 \\
\cline { 2 - 8 } & AramcoMech & 2.28 & 2.11 & 2.26 & -0.63 & -0.54 & -0.64 \\
\cline { 2 - 8 } & Madison & 2.27 & 2.10 & 2.25 & -0.64 & -0.55 & -0.66 \\
\hline
\end{tabular}

Table 8 presents the $\alpha$ and $\beta$ coefficients calculated from experimental data and data from the kinetic mechanisms. A few key conclusions can be drawn from the results:

- for downdraft mixtures the temperature effect is overestimated by all mechanisms;

- the temperature effect on the fluidbed mixture decreases sharply with the increase in equivalence ratio;

- the AramcoMech and CRECK mechanisms present similar coefficients for downdraft and updraft mixtures. That is consistent with the fact that 
both mechanisms are based in part on the mechanism of Metcalfe et al [46].

\subsection{Markstein Length}

Figure 8 presents Markstein length $\left(L_{b}\right)$ results as compared to Monteiro et

al. 24]. An increase in Markstein length with equivalence ratio is shown for all compositions. Markstein lengths are negative for lean mixtures and they transition to positive near $\phi=1$ for all compositions. When comparing the present work with Monteiro's data a global agreement is found with the exception of equivalence ratios of 0.6 and 1.2. The small number of data points in Monteiro's data makes it difficult to identify the same relation between Markstein length and the equivalence ratio. It is important to note the difference in behavior between fluidbed and the two other mixtures: the drop in Markstein length at low equivalence ratios is considerably more pronounced. This behavior is consistent with the findings of Zhou et al. [23, which showed a reduction in $L_{b}$ with higher $\mathrm{CO}_{2}$ dilution. The fluidbed composition differentiates itself from the other two compositions by the higher $\mathrm{CO}_{2}$ and $\mathrm{CH}_{4}$ mole fractions (see figure 1]. Anggono et al. 47] has found that high $\mathrm{CO}_{2}$ dilution rates can increase significantly stretch sensitivity of $\mathrm{CH}_{4} / \mathrm{CO}_{2} /$ air flames. This could also be due to the increase in shot-to-shot variation on lean mixtures at low temperatures, but Figure 9 seems to indicate that the same trend is present at higher temperatures. Further study on the effect of each syngas component on Markstein length is needed in order to definitely explain this phenomenon. 


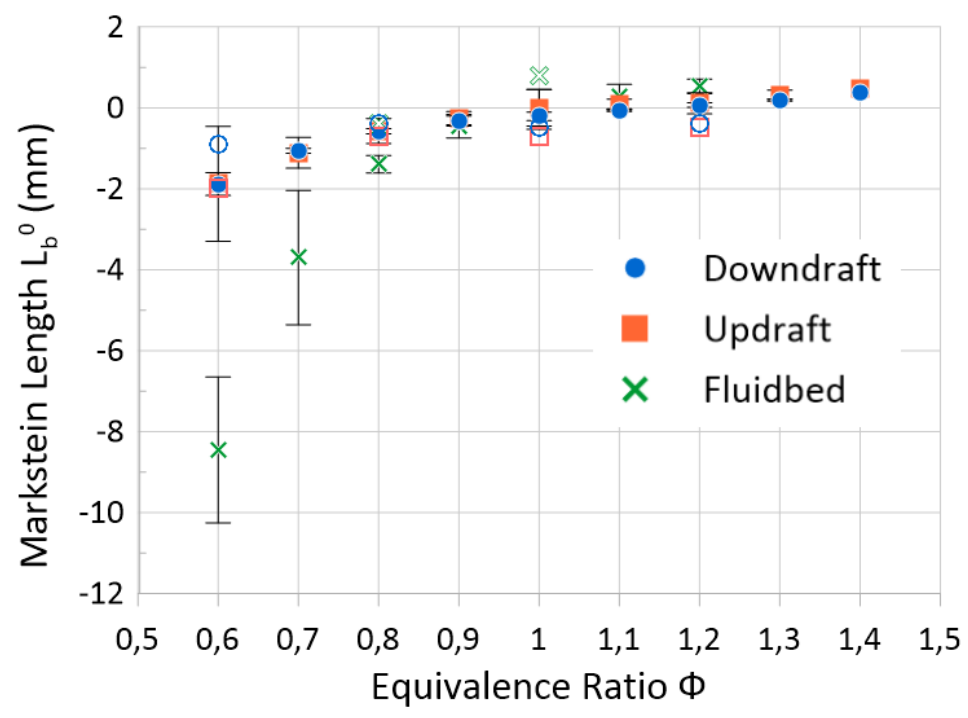

Figure 8: Present work experimental Markstein length results at 1 bar $298 \mathrm{~K}$ (filled symbols) compared to Monteiro et al. 24 results at 1 bar $293 \mathrm{~K}$ (unfilled symbols).

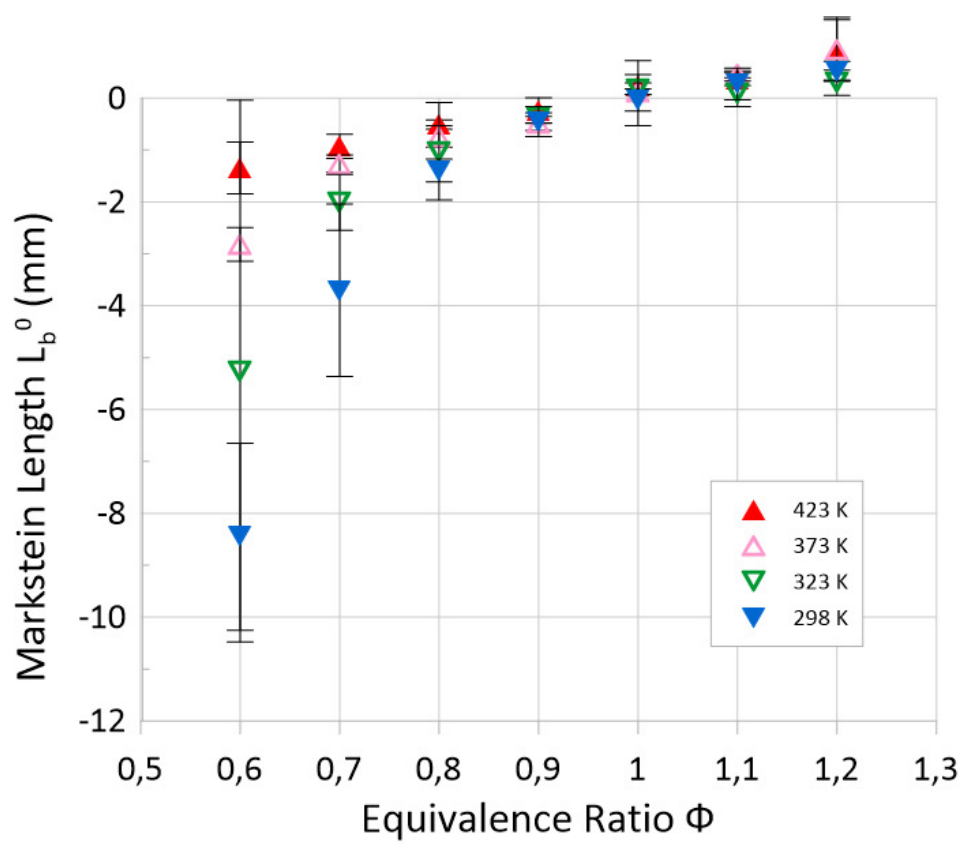

Figure 9: Markstein length results of the fluidbed composition for different temperatures and equivalence ratios. 


\section{Conclusion}

275 compositions as a function of equivalence ratio, initial temperature (up to 423 $\mathrm{K}$ ) and initial pressure (up to 5 bar). The main conclusions that can be drawn from these results are:

- the experimental data obtained shows good agreement with the two litera-

ture results for lean mixtures but the same cannot be said for rich mixtures where, in some cases, the same maximum flame speed is not obtained;

- at $298 \mathrm{~K}$ and 1 bar fluidbed, updraft and downdraft laminar flame speeds peak at 14,31 and $37 \mathrm{~cm} / \mathrm{s}$ respectively;

- Markstein lengths tend to start negative for lean mixtures and change to positive around stoichiometry,

- better agreement of experimental data with kinetic mechanism predictions is obtained when compared to data from literature: the CRECK and San Diego mechanisms are especially accurate, compared to Aramco and Madison mechanisms;

- a classical correlation, based on the work of Metghalchi and Keck 28, indicated an acceptable agreement for $\mathrm{S}_{u}^{0}$ (less than $5 \%$ of inaccuracy on average).

\subsection{Perspectives and future work}

In future work, the laminar flame speeds of dual-fuel mixtures of syngas and diesel surrogates will be measured. The Madison mechanism seems to be a

good starting point when predicting laminar flame speed of syngas mixed with heavier fuels like decane.

The laminar flame speed data obtained for syngas and syngas/decane mixtures can be valuable when validating a reduced kinectic mechanism for CFD dual-fuel engine simulations. 


\section{Acknowledgment}

The research leading to these results has received funding from the French Government's "Investissement d'Avenir" program: "Laboratoire d'Excellence CAPRYSSES" (Grant No ANR-11-LABX-0006-01) and Région Centre-Val de Loire.

\section{References}

[1] 2030 climate energy framework, https://ec.europa.eu/clima/ policies/strategies/2030_en, accessed: 2020-02-03.

[2] M. Costa, D. Piazzullo, Biofuel Powering of Internal Combustion Engines: Production Routes, Effect on Performance and CFD Modeling of Combustion, Frontiers in Mechanical Engineering 4 (August) (2018) 1-14. doi:10.3389/fmech.2018.00009.

[3] Biofuels dashboard 2019 by ifpen, https://www.ifpenergiesnouvelles. com/article/biofuels-dashboard-2019.

[4] F. Y. Hagos, A. R. A. Aziz, S. A. Sulaiman, Trends of syngas as a fuel in internal combustion engines, Advances in Mechanical Engineering 2014. doi:10.1155/2014/401587.

[5] R. Bates, K. Dölle, Syngas Use in Internal Combustion Engines - A Review, Advances in Research 10 (1) (2017) 1-8. doi:10.9734/air/2017/32896.

320 [6] B. B. Sahoo, U. K. Saha, N. Sahoo, Theoretical performance limits of a syngas-diesel fueled compression ignition engine from second law analysis Energy 36 (2) (2011) 760-769. doi:10.1016/j.energy.2010.12.045. URL http://dx.doi.org/10.1016/j .energy .2010.12.045

[7] F. Y. Hagos, A. Rashid, A. Aziz, S. A. Sulaiman, Study of syngas combustion parameters effect on internal combustion engine, Asian Journal of Scientific Research 6 (2) (2013) 187-196. doi:10.3923/ajsr.2013.187.196 
[8] B. K. Mahgoub, S. A. Sulaiman, Z. A. Karim, Performance study of imitated syngas in a dual-fuel compression ignition diesel engine, International Journal of Automotive and Mechanical Engineering 11 (1) (2015) 2282-2293. doi:10.15282/ijame.11.2015.11.0192.

[9] A. L. Boehman, O. Le Corre, Combustion of syngas in internal combustion engines, Combustion Science and Technology 180 (6) (2008) 1193-1206. doi:10.1080/00102200801963417.

[10] H. Guo, W. S. Neill, B. Liko, The combustion and emissions performance of a syngas-diesel dual fuel compression ignition engine, ASME 2016 Internal Combustion Engine Fall Technical Conference, ICEF 2016 (January 2018). doi:10.1115/ICEF20169367.

[11] P. Rosha, A. Dhir, S. Kumar, In fl uence of gaseous fuel induction on the

1 various engine characteristics of a dual fuel compression ignition engine : A review, Renewable and Sustainable Energy Reviews 82 (September 2017) (2018) 3333-3349. doi:10.1016/j.rser.2017.10.055. URL https://doi.org/10.1016/j.rser.2017.10.055

[12] S. Karthikeyan, M. Periyasamy, G. Mahendran, Assessment of engine performance using syngas, Materials Today: Proceedings (xxxx) (2020) 6-8. doi:10.1016/j.matpr.2020.06.577.

URL https://doi.org/10.1016/j.matpr.2020.06.577

[13] H. Yu, W. Han, J. Santner, X. Gou, C. H. Sohn, Y. Ju, Z. Chen, Radiationप induced uncertainty in laminar flame speed measured from propagating

1 Spherical flames, Combustion and Flame 161 (11) (2014) 2815-2824. doi:

$350 \quad 10.1016 / \mathrm{j}$.combustflame.2014.05.012.

URL http://dx.doi.org/10.1016/j . combustflame.2014.05.012

[14] E. Monteiro Magalhaes, Combustion Study of Mixtures Resulting From a Gasification Process of Forest Biomass, Ph.D. thesis (2011). 
[15] C. Lhuillier, P. Brequigny, N. Lamoureux, F. Contino, C. Mounaïm-

Rousselle, Experimental investigation on laminar burning velocities of ammonia/hydrogen/air mixtures at elevated temperatures, Fuel 263 (November 2019) (2020) 116653. doi:10.1016/j.fuel.2019.116653

URL https://doi.org/10.1016/j.fuel.2019.116653

[16] C. Prathap, A. Ray, M. R. Ravi, Investigation of nitrogen dilution effects on the laminar burning velocity and flame stability of syngas fuel at atmospheric condition, Combustion and Flame 155 (1-2) (2008) 145-160. doi:10.1016/j.combustflame.2008.04.005. URL http://dx.doi.org/10.1016/j.combustflame.2008.04.005

[17] Y. Xie, X. Wang, H. Bi, Y. Yuan, J. Wang, Z. Huang, B. Lei, A com365 prehensive review on laminar spherically premixed flame propagation of

1. Syngas, Fuel Processing Technology 181 (September) (2018) 97-114. doi: 10.1016/j.fuproc.2018.09.016.

URL https://doi.org/10.1016/j.fuproc.2018.09.016

[18] N. Bouvet, C. Chauveau, I. Gökalp, F. Halter, Experimental studies of the fundamental flame speeds of syngas ( $\mathrm{H}$ 2/CO)/air mixtures, Proceedings of

口 the Combustion Institute 33 (1) (2011) 913-920. doi:10.1016/j.proci. 2010.05 .088

[19] S. Wang, Z. Wang, X. Han, C. Chen, Y. He, Y. Zhu, K. Cen, Experimental

n and numerical study of the effect of elevated pressure on laminar burning 375 velocity of lean $\mathrm{H} 2 / \mathrm{CO} / \mathrm{O} 2 /$ diluents flames, Fuel 273 (November 2019) (2020) 117753. doi:10.1016/j.fuel.2020.117753

URL https://doi.org/10.1016/j.fuel.2020.117753

[20] R. Shang, Y. Zhang, M. Zhu, Z. Zhang, D. Zhang, G. Li, Laminar flame speed of $\mathrm{CO} 2$ and $\mathrm{N} 2$ diluted $\mathrm{H} 2 / \mathrm{CO} /$ air flames, International Journal of 380 ㄱ. Hydrogen Energy 41 (33) (2016) 15056-15067. doi:10.1016/j.ijhydene. 2016.05 .064

URL http://dx.doi.org/10.1016/j.ijhydene.2016.05.064 
[21] D. Lapalme, F. Halter, C. Mounaïm-Rousselle, P. Seers, Characterization of

n thermodiffusive and hydrodynamic mechanisms on the cellular instability of syngas fuel blended with CH4 or CO2, Combustion and Flame 193 (2018) 481-490. doi:10.1016/j.combustflame.2018.03.028.

URL https://doi.org/10.1016/j.combustflame.2018.03.028

[22] Y. Xie, Q. Li, A review on mixing laws of laminar flame speed and their applications on $\mathrm{H} 2 / \mathrm{CH} 4 / \mathrm{CO} /$ air mixtures, International Journal of Hydrogen Energy 45 (39) (2020) 20482-20490. doi:10.1016/j.ijhydene.2019. 10.136 .

URL https://doi.org/10.1016/j.ijhydene.2019.10.136

[23] Q. Zhou, C. S. Cheung, C. W. Leung, X. Li, Z. Huang, Effects of diluents on laminar burning characteristics of bio-syngas at elevated pressure, Fuel 248 (December 2018) (2019) 8-15. doi:10.1016/j.fuel.2019.03.062. URL https://doi.org/10.1016/j.fuel.2019.03.062

[24] E. Monteiro, M. Bellenoue, J. Sotton, N. A. Moreira, S. Malheiro, Laminar burning velocities and Markstein numbers of syngas-air mixtures, Fuel 89 (8) (2010) 1985-1991. doi:10.1016/j.fuel.2009.11.008 URL http://dx.doi.org/10.1016/j.fuel.2009.11.008

[25] E. Monteiro, A. Rouboa, Measurements of the laminar burning velocities for typical syngas-air mixtures at elevated pressures, Journal of Energy Resources Technology, Transactions of the ASME 133 (3) (2011) 1-7. doi: $10.1115 / 1.4004607$

[26] A. Kéromnès, W. K. Metcalfe, K. A. Heufer, N. Donohoe, A. K. Das, C. J. Sung, J. Herzler, C. Naumann, P. Griebel, O. Mathieu, M. C. Krejci, E. L. Petersen, W. J. Pitz, H. J. Curran, An experimental and detailed chemical kinetic modeling study of hydrogen and syngas mixture oxidation at elevated pressures, Combustion and Flame 160 (6) (2013) 995-1011. doi:10.1016/j.combustflame.2013.01.001. 
[27] A. V. Bridgwater, The technical and economic feasibility of biomass gasi-

n fication for power generation, Fuel 74 (5) (1995) 631-653. doi:10.1016/ 0016-2361(95) 00001-L.

[28] M. Metghalchi, J. C. Keck, Burning velocities of mixtures of air with methanol, isooctane, and indolene at high pressure and temperature, Combustion and Flame 48 (C) (1982) 191-210. doi:10.1016/0010-2180(82) 90127-4

[29] M. Di Lorenzo, P. Brequigny, F. Foucher, C. Mounaïm-Rousselle, Valia dation of TRF-E as gasoline surrogate through an experimental laminar burning speed investigation, Fuel 253 (September 2018) (2019) 1578-1588. doi:10.1016/j.fuel.2019.05.081 URL https://doi .org/10.1016/j.fuel.2019.05.081

[30] B. Galmiche, F. Halter, F. Foucher, Effects of high pressure, high temperature and dilution on laminar burning velocities and Markstein lengths of iso-octane/air mixtures, Combustion and Flame 159 (11) (2012) 3286-3299. doi:10.1016/j.combustflame.2012.06.008

[31] C. Endouard, F. Halter, C. Chauveau, F. Foucher, Effects of co2, h2o, and exhaust gas recirculation dilution on laminar burning velocities and markstein lengths of iso-octane/air mixtures, Combustion Science and Technology 188 (4-5) (2016) 516-528. doi:10.1080/00102202.2016.1138792.

[32] S. M. Sarathy, P. Brequigny, A. Katoch, A. M. Elbaz, W. L. Roberts, R. W. Dibble, F. Foucher, Laminar burning velocities and kinetic modeling of a renewable e-fuel: Formic acid and its mixtures with h2 and co2, Energy \& Fuels 34 (6) (2020) 7564-7572. doi:10.1021/acs.energyfuels.0c00944.

435 [33] A. P. Kelley, C. K. Law, Nonlinear effects in the extraction of laminar flame speeds from expanding spherical flames, Combustion and Flame 156 (9) (2009) 1844-1851. doi:10.1016/j.combustflame.2009.04.004. URL http://dx.doi.org/10.1016/j.combustflame.2009.04.004 
[34] F. Halter, T. Tahtouh, C. Mounaïm-Rousselle, Nonlinear effects of stretch

口 on the flame front propagation, Combustion and Flame 157 (10) (2010) 1825-1832. doi:10.1016/j.combustflame.2010.05.013 URL https://linkinghub.elsevier.com/retrieve/pii/ S0010218010001550http://dx.doi.org/10.1016/j.combustflame.

2010.05 .013

[35] X. Gong, J. Huo, Z. Ren, C. K. Law, Extrapolation and DNS-mapping in determining laminar flame speeds of syngas/air mixtures, Combustion and Flame 200 (2019) 365-373. doi:10.1016/j.combustflame.2018.11.033 URL https://doi.org/10.1016/j.combustflame.2018.11.033

[36] W. Han, P. Dai, X. Gou, Z. Chen, A review of laminar flame speeds of hydrogen and syngas measured from propagating spherical flames, Applications in Energy and Combustion Science 1-4 (October) (2020) 100008. doi:10.1016/j.jaecs.2020.100008

URL https://doi.org/10.1016/j.jaecs.2020.100008

[37] P. Brequigny, H. Uesaka, Z. Sliti, D. Segawa, F. Foucher, G. Dayma, Uncertainty in measuring laminar burning velocity from expanding methane-air flames at low pressures, in: 11th Mediterranean Combustion Symposium, no. June, 2019, pp. 16-20.

[38] Z. Chen, Effects of radiation absorption on spherical flame propagation and radiation-induced uncertainty in laminar flame speed measurement Proceedings of the Combustion Institute 36 (1) (2017) 1129-1136. doi: 10.1016/j.proci.2016.05.003.

URL http://dx.doi.org/10.1016/j.proci.2016.05.003

[39] J. C. Prince, C. Treviño, F. A. Williams, A reduced reaction mechanism for the combustion of n-butane, Combustion and Flame 175 (2017) 27-33. doi:10.1016/j.combustflame.2016.06.033

URL http://dx.doi.org/10.1016/j.combustflame.2016.06.033 
[40] G. Bagheri, E. Ranzi, M. Pelucchi, A. Parente, A. Frassoldati, T. Faravelli, Comprehensive kinetic study of combustion technologies for low environmental impact: MILD and OXY-fuel combustion of methane, Combustion and Flame 212 (x) (2020) 142-155. doi:10.1016/j.combustflame.2019. 10.014

[41] S. Ren, S. L. Kokjohn, Z. Wang, H. Liu, B. Wang, J. Wang, A multi-

1 component wide distillation fuel (covering gasoline, jet fuel and diesel fuel) mechanism for combustion and PAH prediction, Fuel 208 (2017) 447-468. doi:10.1016/j.fuel.2017.07.009 URL http://dx.doi.org/10.1016/j.fuel.2017.07.009

[42] C. W. Zhou, Y. Li, U. Burke, C. Banyon, K. P. Somers, S. Ding, S. Khan, J. W. Hargis, T. Sikes, O. Mathieu, E. L. Petersen, M. AlAbbad, A. Farooq, Y. Pan, Y. Zhang, Z. Huang, J. Lopez, Z. Loparo, S. S. Vasu, H. J. Curran, An experimental and chemical kinetic modela ing study of 1,3-butadiene combustion: Ignition delay time and laminar flame speed measurements, Combustion and Flame 197 (2018) 423-438. doi:10.1016/j.combustflame.2018.08.006

URL https://doi .org/10.1016/j.combustflame.2018.08.006

485

口

[43] G. P. Oliveira, M. E. Sbampato, C. A. Martins, L. R. Santos, L. G. Barreta, R. F. Boschi Gonçalves, Experimental laminar burning velocity of syngas from fixed-bed downdraft biomass gasifiers, Renewable Energy 153 (2020) 1251-1260. doi:10.1016/j.renene.2020.02.083

URL https://doi.org/10.1016/j.renene.2020.02.083

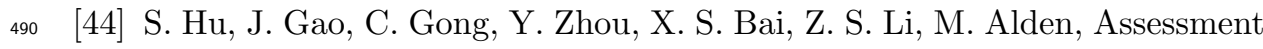
of uncertainties of laminar flame speed of premixed flames as determined using a Bunsen burner at varying pressures, Applied Energy 227 (September 2017) (2018) 149-158. doi:10.1016/j.apenergy.2017.09.083

[45] F. Wu, W. Liang, Z. Chen, Y. Ju, C. K. Law, Uncertainty in stretch extrapolation of laminar flame speed from expanding spherical flames, 
Proceedings of the Combustion Institute 35 (1) (2015) 663-670. doi: 10.1016/j.proci.2014.05.065.

URL http://dx.doi.org/10.1016/j.proci.2014.05.065

[46] W. K. Metcalfe, S. M. Burke, S. S. Ahmed, H. J. Curran, A hierarchical and comparative kinetic modeling study of C1 - C2 hydrocarbon and oxygenated fuels, International Journal of Chemical Kinetics 45 (10) (2013) 638-675. doi:10.1002/kin.20802.

[47] W. Anggono, A. Hayakawa, E. C. Okafor, G. J. Gotama, S. Wongso, Lama inar Burning Velocity and Markstein Length of $\mathrm{CH} 4 / \mathrm{CO} 2 /$ Air Premixed 505 . Flames at Various Equivalence Ratios and CO2 Concentrations Under Elevated Pressure, Combustion Science and Technology 00 (00) (2020) 1-20. doi:10.1080/00102202.2020.1737032.

URL https://doi .org/10.1080/00102202.2020.1737032 